\title{
SPECTRUM OF YELLOW HYPERGIANT $\rho$ CAS DURING 2007-2011
}

\author{
V. G. Klochkova ${ }^{1}$, I. A. Usenko ${ }^{2}$ \\ ${ }^{1}$ Special Astronomical Observatory Russian Academy of Sciences, \\ Nizhnij Arkhys, 369167, Russia, valenta@sao.ru \\ 2 Astronomical Observatory, Odesa National University, \\ T. G. Shevchenko Park, Odesa,65014,Ukraine, igus99@ukr.net
}

(Received December 12, 2011; received in final form October 01, 2012)

\begin{abstract}
Multiple observations carried out during 2007-2011 using high-resolution spectroscopy with $6 \mathrm{~m}$ telescope BTA SAO RAS allowed to search for the peculiar properties of optical and UV spectra and field of velocities in the yellow hypergiant's $\rho$ Cas atmosphere. Radial velocity determined by symmetrical absorptions of metals varies in time relatively to the system's velocity $V_{\text {sys }}=-47 \pm 1 \mathrm{~km} \mathrm{~s}^{-1}$, and this fact is a sequence of small amplitude pulsations of the nearphotospherical atmosphere layers. In the single moments the velocity gradient in the deep layers of stellar atmosphere have been observed. Radial velocity determined using by short-wave components of BaII, Sr II, TiII and other strong lines with low level excitational potential takes place in the narrow limit of $V_{\text {blue }} \sim-60 \div-70 \mathrm{~km} \mathrm{~s}^{-1}$. We suppose that short-wave components form in the circumstellar shell as well as one of the components of sodium doublet lines D Na I.
\end{abstract}

Key words: Stars: Yellow hypergiants, stars: individual: $\rho$ Cas.

PACS number(s): 95.75.Fg, 95.85.Kr, 97.10.Ex, 97.30.Gj

\section{INTRODUCTION}

$\rho$ Cas with its spectral type G2 Iae is a prototype of yellow hypergiants, - massive stars with extremely high luminosity. In the Herzsprung-Russel diagram these objects take place in the instability region near the limit of luminosity (de Jager et al., [1]). These objects evolved rapidly from the red supergiants to Wolf-Rayet stars or LBV ones. The process of moving into the hightemperatures region has been studied very poorly, and this fact account for the expedience of monitoring for yellow hypergiants.

The nearest object in the HR-diagram to $\rho$ Cas is the famous hypergiant V1302 Aql, more known by the name of IRC +10420 , which is the infrared source associated with it. The central star V1302 Aql (spectral type F8 Ia and luminosity near $10^{6} L_{\odot}$ ) has cored up by the gasdust medium and it is a source of $\mathrm{OH}$-maser's power radiation (see Schuster et al. [2]). One of the prior results during the long-term studies was the detection of its effective temperature's rapid growth (Klochkova et al. [3]; Lobel et al. [4]). At that the monitoring data of V1302 Aql during last decades of the 20th century displayed of the effective temperature growth acceleration (Klochkova et al. [5]).

In addition yellow hypergiants differ from the usual supergiants by their high rate of mass loss, dynamical instability of atmospheres, that have revealed in pulsational activity and presence of extensive circumstellar shells. Moreover yellow hypergiants additionally pass over the so-called "shell episodes" when during a shorttime period this star lost a large part of its matter. As a result, during some hundred days this star has been wrapped up by the ejected cool matter that has formed pseudo-photosphere. In case of $\rho$ Cas the last such event took place on the border of 2000-2001 when this star lost about of $3 \times 10^{-2} M_{\odot}($ Lobel et al. [4]).

In this article we present the results of $\rho$ Cas spectroscopy during 2007-2011, taken with the $6 \mathrm{~m}$ telescope BTA. In Section II we describe the methods of observations and data analysis; in Section III we present the results and their comparison with published data, and in Section 4 we give the main conclusions.

\section{OBSERVATIONS, PROCESSING AND ANALYSIS OF SPECTRA}

Spectroscopic data for $\rho$ Cas have been obtained using echelle spectrograph NES in the Nasmyth focus of $6 \mathrm{~m}$ telescope (Panchuk et al. [6]; Panchuk et al. [7]), using CCD-matrix $2048 \times 2048$ or $4096 \times 2048$ elements with an image slicer (Panchuk et al. [7]). Spectral resolution is equal to $\lambda / \Delta \lambda \approx 60000$, signal-to-noise ratio $\mathrm{S} / \mathrm{N} \geq 100$. Average moments of observations (JD) and spectral ranges are given in Table 1 .

The extraction process of one-dimension spectra from two-dimensions echelle-frames was implemented using a modified context ECHELLE of the program complex the MIDAS. Cosmic particles traces removal was carried out by a median averaging-out of two spectra obtained one by one. Wavelength calibration carried out using the spectrum of $\mathrm{Th}-\mathrm{Ar}$ hollow cathode lamp. Instrumental agreement control of stellar and hollow cathode lamp spectra was carried out using telluric lines $\mathrm{O}_{2}$ and $\mathrm{H}_{2} \mathrm{O}$. In $\rho$ Cas the spectra for $V_{\mathrm{r}}$ control we have measured 15-22 telluric lines for spectra with the long-wave region 5930-6010 $\AA$ and 70-80 lines for other long-wave 
ones. The standard error of $V_{\mathrm{r}}$ using narrow telluric absorptions come to $\leq 0.5 \mathrm{~km} \mathrm{~s}^{-1}$ (accuracy from one line). More in detail the procedure of $V_{\mathrm{r}}$ from the spectra ob- tained using NES specrograph and the sourses of errors are described by Klochkova et al. [8].

\begin{tabular}{|l|c|c|c|c|}
\hline Spectrum & Date & $\begin{array}{c}\text { HJD } \\
2450000+\end{array}$ & $\begin{array}{c}\text { Spectral } \\
\text { range, } \AA\end{array}$ & $\begin{array}{c}T_{\text {eff }} \\
(\mathrm{K})\end{array}$ \\
\hline s493015 & 09.03 .2007 & 4168.630 & $4557-6014$ & $6221 \pm 90$ \\
s494023 & 10.03 .2007 & 4169.570 & $4557-6014$ & $6200 \pm 171$ \\
s495019 & 10.03 .2007 & 4170.490 & $4514-5940$ & $6229 \pm 131$ \\
s516015 & 21.02 .2008 & 4518.390 & $5204-6680$ & $6610 \pm 53$ \\
s525032 & 19.10 .2008 & 4759.230 & $3050-4520$ & - \\
s526006 & 20.10 .2008 & 4760.230 & $5214-6690$ & $6744 \pm 53$ \\
s538009 & 30.09 .2009 & 5104.620 & $5216-6691$ & $6420 \pm 39$ \\
s553018 & 01.08 .2010 & 5409.520 & $4422-5930$ & $5777 \pm 161$ \\
s554032 & 23.09 .2110 & 5463.390 & $3970-5390$ & - \\
s555027 & 24.09 .2010 & 5464.390 & $5216-6690$ & $6044 \pm 40$ \\
s564020 & 13.01 .2011 & 5574.600 & $5208-6683$ & $6174 \pm 43$ \\
s565003 & 13.01 .2011 & 5575.140 & $5208-6683$ & $6322 \pm 52$ \\
\hline
\end{tabular}

Table 1. Observations $\log$ of $\rho$ Cas and the results of $T_{\text {eff }}$ determinations

\section{MAIN RESULTS}

\section{A. $\rho$ Cas Effective Temperature}

We determined the effective temperatures $T_{\text {eff }}$ using spectroscopic criteria according to Kovtyukh [9]. This method is based on the depth ratios for selected pairs of spectral lines that are the most sensitive to the temperature. For each pair of lines, analytical relations were found between the depth ratio and the effective temperature $T_{\text {eff }}$. Since one pair of lines allows the effective temperature $T_{\text {eff }}$ to be detemined within $\simeq 50-110 \mathrm{~K}$, a large number of of such pairs of lines (calibrations), the results from which are averaged, are used to increase accuracy. Owing to a large number such calibrations (more than 100 for yellow supergiants), this method provides an internal accuracy in determining $T_{\text {eff }}$ of $\simeq 10-30 \mathrm{~K}$ (the error of the mean). However, while having a high internal accuracy, the scale of effective temperatures used in analysis, can have a fairly large error in its zero point. At present, there are no supergiants with the temperatures accurately determined by direct methods (more accurately than $30-50 \mathrm{~K}$ ). As a result, the error of the scale zero point and the possible systematic error of our temperatures cannot be estimated. However since the method is based on the most reliable published $T_{\text {eff }}$ determinations for a large number of supergiants and Cepheids, we can hope that the error in the zero point is small and is unlikely to exceed 150-200 K (Kovtyukh [9]). Such an error has no noticeable effect on the results of our abundance analysis.

Nevertheless in the case of $\rho$ Cas we have an internal accuracy $39-53 \mathrm{~K}$ for spectra obtained in the ranges
5200-6700 $\AA$ and $90-171 \mathrm{~K}$ in the $4400-6015 \AA$, respectively. This fact could be explained by a larger number of selected pairs of spectral lines in the red part (further than $6200 \AA$ ) of obtained spectra. For two spectra, s525032 and s554032 we cannot determined the $T_{\text {eff }}$ values because of absence of any pairs of spectral lines from Kovtyukh [9] list (see Table 1).

\section{B. Peculiarity and Profiles Variability of Spectral Details}

The profiles of the majority of strong lines of metals in $\rho$ Cas spectra are variable. As a rule as they are asymmetric: their short-wave wings are either elevated under continuum by the variable emission or they have an extention, much more in comparison with the long-wave wing. As a good example is Ba II $6141 \AA$ line that has been represented in the left fragment of Figure 1 in the "residual intensity vs. heliocentrical radial velocity" coordinates. The short-wave wing of Ba II $6141 \AA$ has been formed by the impact of stellar wind reach in the single moments to $-120 \mathrm{~km} \mathrm{~s}^{-1}$, and for the date 20.10.2008 even farther: $-170 \mathrm{~km} \mathrm{~s}^{-1}$. A variability of extensive short-wave wings is a feature of stellar wind variability demonstration.

Besides of extensive short-wave wings the strongest absorptions in $\rho$ Cas spectra have the peculiarities in line cores split by the two components too. The strong lowexcitational absorptions splitting in the spectra of $\rho$ Cas have been known for many decades already (see references in Lambert et al. [11]). More than 50 years ago Sargent [12] gave a long list of these spectral details.

A large spectral interval registered by us detected these absorptions: from 16 in the visual range (5100-6500 
$\AA)$ to 43 in the short-wave $(3900-5000 \AA)$ one. The list of absorptions with core splitting is given in Table 2. All the lines with the wavelength more than $5100 \AA$ were represented earlier in the list from Sargent [12]. All the possible reasons that have caused this splitting we will consider in the next item to be devoted to the field of velocities analysis.

For the six observational moments the registered spectral range has the $\mathrm{H}_{\alpha}$ line. Complicated absorptional-toemissional profile of $\mathrm{H}_{\alpha}$ has changed with time: the position of its absorptional core, intensity of emission components and their intensities ratio have changed (see the details in Fig. 2). $\mathrm{H}_{\alpha}$ absorptional core position change has pointed out that the region of its forming in the stellar atmosphere is unstable. We will note that during the period of our observations the $\mathrm{H}_{\alpha}$ core offset comes to $\approx 16 \mathrm{~km} \mathrm{~s}^{-1}$, while in the earlier observations of Lobel et al. [13] the core shift to $35 \mathrm{~km} \mathrm{~s}^{-1}$ has been noted.
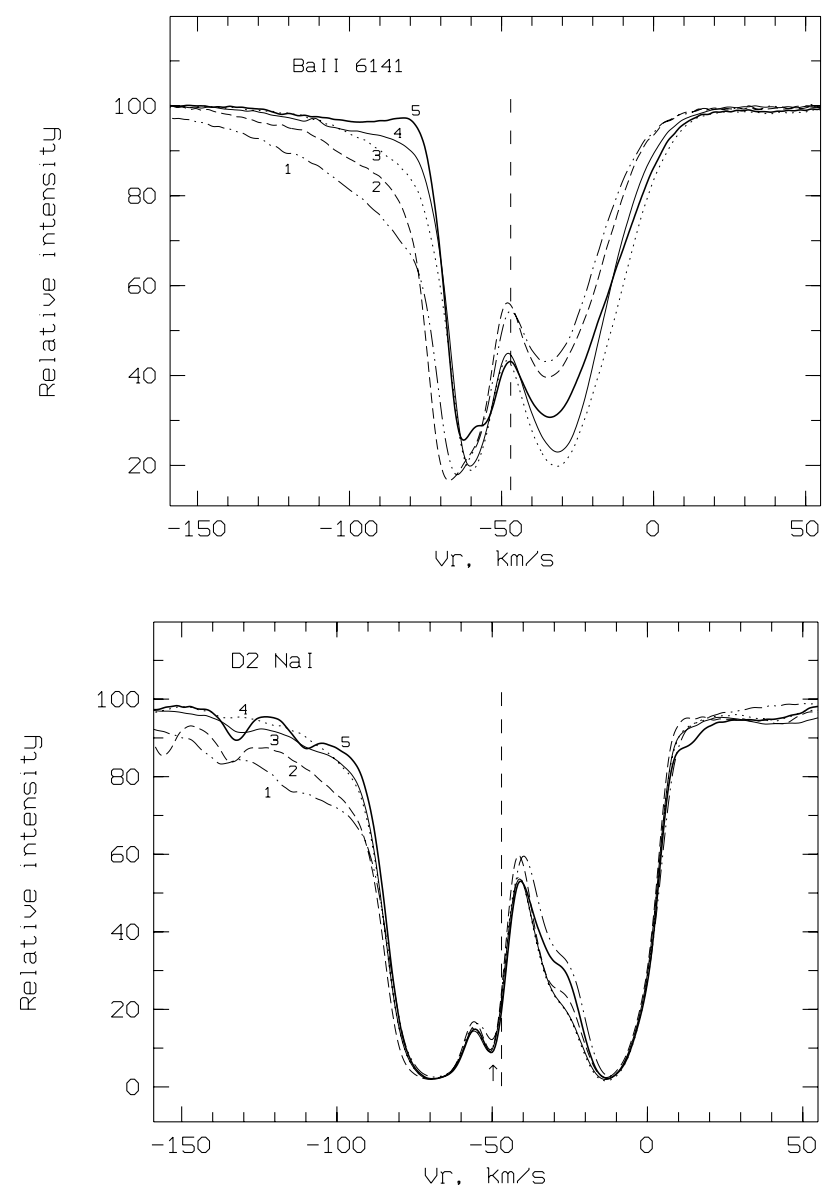

Fig. 1. Ba II $6141 \AA$ and D2 Na I $5889 \AA$ in the $\rho$ Cas spectra in different observational moments: 1 - JD 2454760.2; 2 - JD 2455575.3; 3 - JD 2454518.4; 4 - JD 2455654.4; 5 - JD 2455409.5. The position of the interstellar component $V_{\mathrm{r}}(\mathrm{IS}) \approx-49.7 \mathrm{~km} \mathrm{~s}^{-1}$ (Georgelin \& Georgelin [10]) marked off by the arrow. $V_{\mathrm{sys}}=-47 \mathrm{~km} \mathrm{~s}^{-1}$ marked off by the vertical dash line.

\begin{tabular}{|c|c|c|}
\hline $\begin{array}{l}\text { Element } \\
\text { ion }\end{array}$ & $\begin{array}{c}\text { Wavelength } \\
\AA\end{array}$ & $\begin{array}{c}\chi_{\text {low }} \\
\mathrm{eV}\end{array}$ \\
\hline 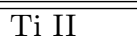 & 3913.47 & 0.95 \\
\hline $\mathrm{Fe} I$ & 3920.26 & 0.97 \\
\hline Fe I & 3922.91 & 0.97 \\
\hline Y II & 3950.36 & 0.90 \\
\hline Fe I & 4005.24 & 1.56 \\
\hline Ti II & 4012.38 & 0.57 \\
\hline Mn I & 4030.75 & 0.00 \\
\hline Mn I & 4033.06 & 0.00 \\
\hline Mn I & 4034.48 & 0.00 \\
\hline Fe I & 4045.81 & 1.48 \\
\hline $\mathrm{Fe} I$ & 4063.59 & 1.56 \\
\hline Fe I & 4071.74 & 1.61 \\
\hline $\mathrm{Sr}$ II & 4077.71 & 0.00 \\
\hline Fe I & 4132.06 & 1.61 \\
\hline Fe I & 4143.87 & 1.56 \\
\hline $\mathrm{Fe} I$ & 4202.03 & 1.48 \\
\hline $\mathrm{Sr}$ II & 4215.52 & 0.00 \\
\hline $\mathrm{Ca} \mathrm{I}$ & 4226.73 & 0.00 \\
\hline Sc II & 4246.82 & 0.32 \\
\hline Fe I & 4250.79 & 1.56 \\
\hline Fe I & 4271.76 & 1.48 \\
\hline Fe I & 4294.12 & 1.48 \\
\hline Ti II & 4300.04 & 1.18 \\
\hline $\mathrm{Fe} I$ & 4307.90 & 1.56 \\
\hline Fe I & 4325.76 & 1.61 \\
\hline Ti II & 4330.70 & 1.18 \\
\hline Ti II & 4337.91 & 1.09 \\
\hline Fe I & 4383.54 & 1.48 \\
\hline Ti II & 4395.03 & 1.08 \\
\hline $\mathrm{Fe} I$ & 4404.75 & 1.56 \\
\hline $\mathrm{Sc} \mathrm{II}$ & 4415.55 & 0.60 \\
\hline Ti II & 4417.71 & 1.16 \\
\hline Fe I & 4427.31 & 0.05 \\
\hline Ti II & 4443.80 & 1.08 \\
\hline $\mathrm{Fe} \mathrm{I}$ & 4461.65 & 0.08 \\
\hline Ti II & 4468.51 & 1.13 \\
\hline Ti II & 4501.27 & 1.12 \\
\hline Ti II & 4533.96 & 1.24 \\
\hline Ti II & 4549.62 & 1.58 \\
\hline $\mathrm{Ba} I I$ & 4554.03 & 0.00 \\
\hline Ti II & 4563.76 & 1.22 \\
\hline Ti II & 4571.97 & 1.57 \\
\hline $\mathrm{Ba}$ II & 4934.08 & 0.00 \\
\hline Ti II & 5129.16 & 1.89 \\
\hline $\mathrm{Fe} I \mathrm{II}$ & 5169.03 & 2.89 \\
\hline $\mathrm{Mg} \mathrm{I}$ & 5172.70 & 2.71 \\
\hline $\mathrm{Mg} \mathrm{I}$ & 5183.62 & 2.71 \\
\hline $\mathrm{Fe} \mathrm{I}$ & 5269.54 & 0.85 \\
\hline $\mathrm{Fe} I$ & 5328.04 & 0.92 \\
\hline Fe I & 5371.49 & 0.96 \\
\hline Fe I & 5397.13 & 0.92 \\
\hline Fe I & 5405.77 & 0.99 \\
\hline $\mathrm{Fe} \mathrm{I}$ & 5429.70 & 0.96 \\
\hline Fe I & 5434.52 & 1.01 \\
\hline Fe I & 5446.92 & 0.99 \\
\hline Fe I & 5455.62 & 1.01 \\
\hline Ba II & 5853.67 & 0.60 \\
\hline $\mathrm{Ba}$ II & 6141.71 & 0.70 \\
\hline $\mathrm{Ba}$ II & 6496.90 & 0.60 \\
\hline
\end{tabular}

Table 2. List of splitting lines in $\rho$ Cas spectra 


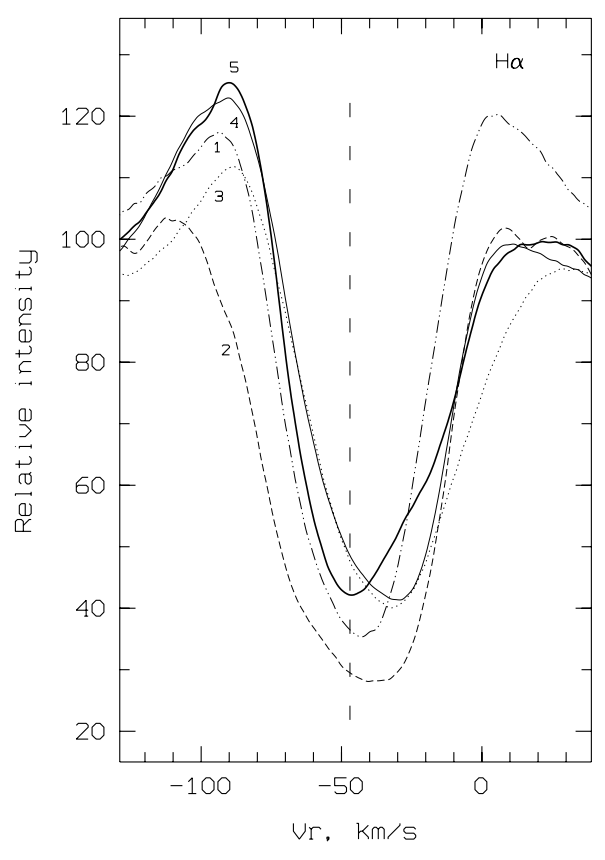

Fig. 2. Central part of $\mathrm{H}_{\alpha}$ line profile in the $\rho$ Cas spectra in the different observational moments: 1 - JD 2454760.2; 2 - JD 2455575.3; 3 - JD 2454518.4; 4 - JD 2455654.4; 5 JD 2455409.5. $V_{\mathrm{sys}}=-47 \mathrm{~km} \mathrm{~s}^{-1}$ marked off by the vertical dash line.

\section{Field of velocities in the atmosphere and core of $\rho$ Cas}

Systemic velocity of $\rho$ Cas. Lambert et al. [11] using IR observations determined the systemic heliocen- trical velocity $V_{\text {sys }}=-48 \pm 2 \mathrm{~km} \mathrm{~s}^{-1}$. Lobel et al. [14] used as a systemic velocity $V_{\text {sys }}=-42 \mathrm{~km} \mathrm{~s}^{-1}$, but in a later article (Lobel et al. [13]) the value $V_{\text {sys }}=$ $-47 \pm 1 \mathrm{~km} \mathrm{~s}^{-1}$ have been adopted. In this paper we have used $-47 \pm 1 \mathrm{~km} \mathrm{~s}^{-1}$ according to the results from Lobel et al. [13]. However, it would be noted that from the belonging of $\rho$ Cas to Cas OB5 stellar association we could adopt $V_{\text {sys }}=-44 \mathrm{~km} \mathrm{~s}^{-1}$, to be averaged from the radial velocities of five members of this association according to Humphreys [15].

Radial velocity measured from symmetrical absorptions. Due to a wide wavelength range and high precision of radial velocity measurements from single lines, the field of velocities was studied by using a record high number of single symmetrical (more than a few hundreds ones in each spectrum) and splitting lines. Large data files of the individual spectral details, to be got and allowed by us to obtain principally new results to display radial velocities behaviour, are the distinction of our investigation from the approach to the problem from Lobel et al. [4]. In this paper Lobel et al. [4] have used only small fragments of spectra $45 \AA$ length, centred on the wavelength $5187 \AA$, to make a radial velocity monitoring. $V_{\mathrm{r}}$ values from emissions and absorptions in $\rho$ Cas spectra have a great scattering from $-10 \mathrm{~km} \mathrm{~s}^{-1}$ to $-70 \mathrm{~km} \mathrm{~s}^{-1}$. However, according to Figure 3 , displayed $V_{\mathrm{r}}$ relations from the intensity (deep) of corresponding lines, there are some sharply separable sufficient groups of lines. The measurements results of $\rho$ Cas heliocentrical radial velocity for separable groups of lines for all observational moments are given in Table 3 . In the columns entitled as NL we give the number of the lines used for the averaged velocity for the given group.

\begin{tabular}{|l|c|c|c|c|c|c|l|l|}
\hline \multirow{2}{*}{ Spectrum } & Date & \multicolumn{9}{|c|}{$V_{\mathrm{r}}, \mathrm{km} \mathrm{s}^{-1}$} \\
\cline { 3 - 8 } & & sym & NL & blue & NL & red & NL & $\mathrm{HI}_{\text {abs }}$ \\
\hline s493015 & 09.03 .2007 & $-54.4 \pm 0.1$ & 613 & $-65.5 \pm 0.4$ & 12 & $-34.9 \pm 0.4$ & 12 & $-46.5^{1}$ \\
s494023 & 10.03 .2007 & $-54.9 \pm 0.1$ & 556 & $-66.9 \pm 0.6$ & 16 & $-35.0 \pm 0.4$ & 16 & $-47.4^{1}$ \\
s495019 & 10.03 .2007 & $-54.6 \pm 0.1$ & 658 & $-67.3 \pm 0.4$ & 17 & $-34.1 \pm 0.4$ & 16 & $-46.3^{1}$ \\
s516015 & 21.02 .2008 & $-43.8 \pm 0.1$ & 519 & $-61.7 \pm 0.5$ & 12 & $-37.3 \pm 0.5$ & 11 & $-40.0^{2}$ \\
s525032 & 19.10 .2008 & $-40.9 \pm 0.1$ & 259 & $-65.8 \pm 0.1$ & 19 & $-34.4 \pm 0.2$ & 83 & $-49.1^{3},-46.1^{4}$ \\
s526006 & 20.10 .2008 & $-51.1 \pm 0.1$ & 519 & $-62.2 \pm 0.4$ & 12 & $-37.1 \pm 0.5$ & 12 & $-44.6^{2}$ \\
s538009 & 30.09 .2009 & $-43.2 \pm 0.2$ & 483 & $-62.8 \pm 0.2$ & 12 & $-34.3 \pm 0.4$ & 12 & $-46.2^{2}$ \\
s553018 & 01.08 .2010 & $-39.2 \pm 0.1$ & 551 & $-61.8 \pm 0.3$ & 11 & $-32.6 \pm 0.3$ & 11 & $-40.2^{1}$ \\
s554032 & 23.09 .2110 & $-39.0 \pm 0.1$ & 738 & $-60.1 \pm 0.2$ & 45 & $-31.3 \pm 0.2$ & 46 & $-36.4^{1},-36.4^{3},-35.0^{4}$ \\
s555027 & 24.09 .2010 & $-40.1 \pm 0.2$ & 411 & $-60.3 \pm 0.4$ & 12 & $-33.4 \pm 0.4$ & 12 & $-30.2^{2}$ \\
s564020 & 13.01 .2011 & $-43.7 \pm 0.2$ & 473 & $-59.6 \pm 0.3$ & 11 & $-32.9 \pm 0.4$ & 12 & $-30.2^{2}$ \\
s565003 & 13.01 .2011 & $-43.8 \pm 0.2$ & 548 & $-60.1 \pm 0.4$ & 12 & $-33.9 \pm 0.4$ & 12 & $-30.2^{2}$ \\
\hline
\end{tabular}

$\mathrm{NL}$ - number of lines

$1-\mathrm{H}_{\beta}$ line core;

$2-\mathrm{H}_{\alpha}$ line core;

$3-\mathrm{H}_{\delta}$ line core;

$4-\mathrm{H}_{\gamma}$ line core;

Table 3. The results of $\rho$ Cas heliocentrical radial velocity measurements. $V_{\mathbf{r}}(\mathrm{sym})$ - average velocity from symmetrical absorptions, $V_{\mathrm{r}}$ (blue) - from short-wave, $V_{\mathrm{r}}(\mathrm{red})$ - from long-wave components of splitting absorptions; $V_{\mathrm{r}}\left(\mathrm{HI}_{\mathrm{abs}}\right)-$ the one from neutral hydrogen absorptional core 

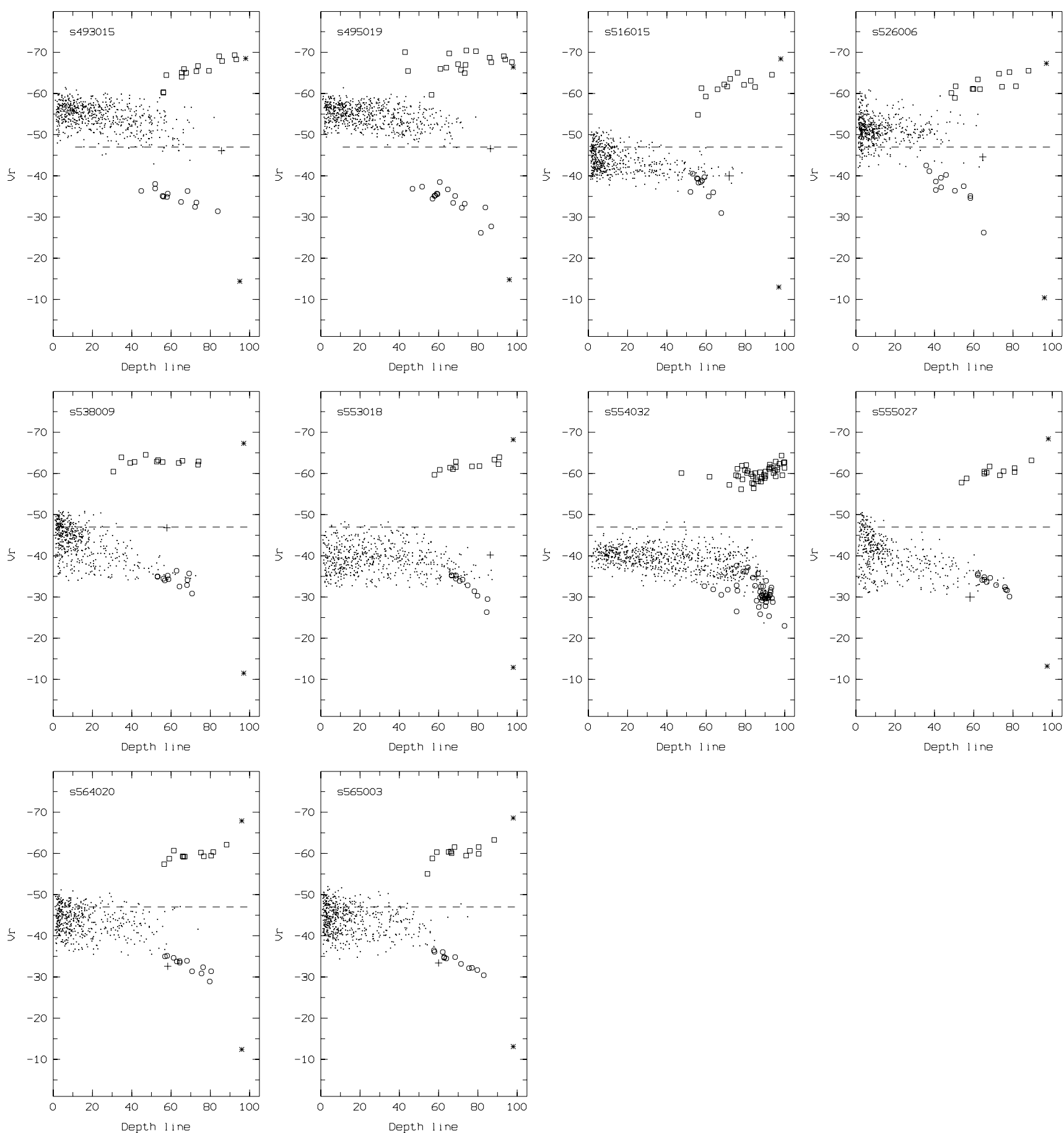

Fig. 3. Relation of $V_{\mathrm{r}}$ measured from the core absorption for its central residual intensity. Dots - single absorptions of symmetrical metals lines; squares - short-wave and circles - long-wave components of split absorptions. The position of absorptional components of HI lines marked off by the cross, short- and long-wave components of D Na I lines, - by the stars. $V_{\text {sys }}=-47 \mathrm{~km} \mathrm{~s}^{-1}$ marked off by the horizontal dash line.

The first group includes the overwhelming majority of spectral details, - single moderate intensity symmetrical lines of metals. The average values of radial velocity, corresponding to the positions of these absorptions are given in the third column of Table 3 . As seen from Table 3 and Figure 3 , the value of $V_{\mathrm{r}}(\mathrm{sym})$ measured confidently using the majority of symmetrical absorptions, reveal changes from date to date. These changes with the amplitude of some $\mathrm{km} \mathrm{s}^{-1}$ are the demonstration of pulsations. In single moments (see, for example the data of spectra, obtained on 30.09.2009 and 24.09.2010) the relation of radial velocity from the line residual intensity is evident, and this fact points out to the existence of the velocity gradient in the stellar atmosphere.

Components of split absorptions. The second group of lines are the short-wave components of splitting lowexcited absorptions. As it has been mentioned above, Table 2 contains the list of these lines: identification and 
wavelengths are given according to the spectral atlas from Klochkova et al. [16], whereas the low level excitational potentials were selected from VALD (Piskunov et al. [17]; Kupka et al. [18]) database.

In the 4 th column of Table 2 we give the present group of lines-averaged radial velocity value $V_{\mathrm{r}}$ (blue) for each date of observations. We have note two principal moments. Firstly, the short-wave components position is close to the one of $\mathrm{CO}$ line core in the near IR range (Lambert et al. [11]; Gorlova et al. [19]) that in case of star with F- spectral type can be formed in the circumstellar shell only.

Secondly, as seen from Figure $3, V_{\mathrm{r}}$ (blue) determined from the short-wave components is not a constant value. It changes from date to date, moreover, for single moments the velocity gradient takes place: from less deep to the deepest lines $V_{\mathrm{r}}$ (blue) changes to $5-6 \mathrm{~km} \mathrm{~s}^{-1}$. We stress that this velocity gradient in the shell detected by us for the first time. The probability of the outflow velocity gradient presence was noted by Sargent [12]. Later Lambert et al. [11] pointed out for the possible existence of this velocity gradient in the circumstellar shell to explain the asymmetry of $\mathrm{CO}$ molecule line profile.

Third group of lines are the long-wave components of splitting absorptions. In the 5th column of Table 3 we give the present group lines-averaged radial velocity value $V_{\mathrm{r}}$ (red) for each date of observations. In the region of forming these long-wave components of splitting absorptions the velocity gradient is present too, moreover, it is more strongly pronounced in comparison with the shortwave ones, and for the single moments of observations (for example 20.10.2008) it has exceded $15 \mathrm{~km} \mathrm{~s}^{-1}$. The trend of velocity in the relation of line depth is often as a prolongation of this one for non-splitting lines (Figure 3 ). The velocity gradient from the long- and short-wave components of splitting absorptions give rise to the growth of the error in the mean (see column three and four in Table 3$)$.

We suppose that long-wave components of splitting absorptions are the usual photospheric ones and their forming region and corresponding velocity do not differ from the same for single large intesity absorptions. However for the series of observations (see the spectra obtained 09.03.2007 and 20.10.2008), when single absorptional velocity do not depend from their intensity, long-wave splitting absorptions components gradient to be remained, and consequently the velocity jump by the pass from the single absorptions to long-wave components of splitting lines has been observed (see Figure 3).

Concerning the short-wave components of splitting absorptions it could be considered, of course, that they have formed in the circumstellal shell. As a confirmation of this fact is a consistency of short-wave components $V_{r}$ (blue) value with the $\mathrm{CO}$ line profile velocity (Lambert et al. [11]). As it should be seen from Table 2 and 3 the shell extension velocity, where shell absorptions have been formed, has changes during the time in the small interval of values: from -59.6 to $-65.5 \mathrm{~km} \mathrm{~s}^{-1}$. Moreover, in the singe moments (20.10.2008 and 13.01.2011) some small (some kilometers per second) shell spread- ing velocity gradient has been observed. At that the CO profile velocity to be formed in the highest upper shell stellar atmospheric layers ensuring continuation of the shell spreading velocity, to be observed by the strong absorptions.

Other lines. Besides the lines mentioned above for all the spectra containing the neutral hydrogen lines we give the velocity $V_{\mathrm{r}}\left(\mathrm{HI}_{\mathrm{abs}}\right)$ measured from the absorptional components of $\mathrm{H}_{\delta}, \mathrm{H}_{\gamma}, \mathrm{H}_{\beta}$ and $\mathrm{H}_{\alpha}$ lines.

D Na I lines profiles besides of the wide components are similar to the ones that we can observe for the strongest absorptions containing the narrow one with $V_{\mathrm{r}}=-48.9 \mathrm{~km} \mathrm{~s}^{-1}$ and the poorly separating component in our spectra near $V_{r} \approx-29 \mathrm{~km} \mathrm{~s}^{-1}$. Absorption with $V_{\mathrm{r}} \approx-50 \mathrm{~km} \mathrm{~s}^{-1}$ has an interstellar origin and it agrees for $\rho$ Cas position within the Perseus arm (Georgelin \& Georgelin [10]). Interstellar NaI line that agrees with the Local Arm, does not separate from the long-wave photospheric component.

In the paper of Gesicki [20] due to $\rho$ Cas spectra obtained in 1969-70, the temporal behaviour of the $\mathrm{Ba}$ II $4934 \AA$ and $5843 \AA$ with Fe I $5328 \AA$ lines have been studied. The main Gesicki's conclusion consists in the fact that short-wave component forms in the circumstellar shell with the maximum gas temperature $\approx 12000 \mathrm{~K}$. Our results confirm this conclusion. However, Gesicki [20] on the basis of $\rho$ Cas spectral monitoring arrived at a conclusion that both the components of splitting lines keep the $V_{\mathrm{r}}$ value during the whole pulsational period. Our high-precision measurements show that both the components of splitting absorptions positions have changed over time with the amplitude of a few $\mathrm{km} \mathrm{s}^{-1}$.

In recent years Lobel with co-authors (Lobel et al. [14]; Lobel et al. [13]; Gorlova et al. [19]) have proposed another explanation of the low-excitation absorptions splitting in the $\rho$ Cas spectra: these wide absorptions with saturated cores separation for two components reasoned by the superposition of stationary emission with $V_{\mathrm{r}} \approx-50 \mathrm{~km} \mathrm{~s}^{-1}$ that has formed in the interstellar medium. The main arguments of these authors against the proposition about the short-wave components formed in the interstellar medium consist in the following facts (Gorlova et al. [19]). Firstly, the presence of two independent components demands constant presence of layers to be moving out and into stellar center and it excluded by the physical reason. Secondly, the splitting low-exitational absorptoins line profiles variations are not independent.

In the hypergiant atmosphere $\mathrm{V} 1302 \mathrm{Aql}=\mathrm{IRC}+10420$ the layers moving out and falling into the stellar center are present simultaneously (Humphreys et al. [21]).

\section{CONCLUSIONS}

We have analysed the characteristics of 12 highresolution spectra of $\rho$ Cas obtained during the different observational seasons 2007-2011. Stellar effective temperature changes in the range of 5777-6744 K. 
Due to a wide wavelength range the field of velocities have been studied using the record high number of single absorptions (a few hundred ones in each spectrum) and splitting lines (from 16 in the visual range to 43 in the short-wave one).

The field of velocities from the single absorptional lines changes from date to date. In the single moments the dependence of radial velocity from line intencity has been observed and this fact points out to the existence of the radial velocity gradient in the stellar atmosphere. In the long-wave components of splitting absorptions forming region this radial velocity gradient (exceeding $15 \mathrm{~km} \mathrm{~s}^{-1}$ for single moments), at the trend of velocity, depending on the line depth is a prolongation of the same one for the single lines. In the single dates the radial velocity gradients from short-wave components take place too, but they are poorly pronounced and their values do not exceed $6 \mathrm{~km} \mathrm{~s}^{-1}$.
The main conclusion consists in the fact that the longwave components of splitting absorptions are the usual photospherical ones, and their forming region and corresponding radial velocity do not differ for the same for single absorptions. And the short-wave splitting absorptions components form in the expanding circumstellar shell.

\section{ACKNOWLEGEMENTS}

Authors grateful to M.V. Yushkin for the help in observations. This work was carried out by the support of the Russian Fund for Fundamental Studies (projects 0802-00072a and 11-02-00319a) and fundamental research program of the Russian Academy of Sciences Presidium named "Origin, Structure and Evolution of the Universe".
[1] C. de Jager, A. Lobel, H. Niuwenhuijzen, R. Stothers, Mon. Not. R. Astron. Soc. 327, 452 (1999).

[2] M. T. Schuster, R. M. Humphreys, M. Marengo, Astron. J. 131, 603 (2006).

[3] V. G. Klochkova, E. L. Chentsov, V. E. Panchuk, Mon. Not. R. Astron. Soc. 292, 19 (1997).

[4] A. Lobel et al. Astron. J. 583, 923 (2003).

[5] V. G. Klochkova, M. V. Yushkin, E. L. Chentsov, V. E. Panchuk, Astron. Rep. 79, 158 (2002).

[6] V. E. Panchuk, V. G. Klochkova, M. V. Yushkin, I. D. Najdenov, in The UV Universe: Stars From Burth to Death. Proceedings of the Joint Discussion No. 4 during the IAU General Assembly of 2006, edited A. I. Gomez de Castro, M. A. Bastrow (Editorial Complutence, Madrid, 2007), p. 179.

[7] V. E. Panchuk, V. G. Klochkova, M. V. Yushkin, I. D. Najdenov, J. Opt. Technol. 76, 42 (2009).

[8] V. G. Klochkova, V. E. Panchuk, M. V. Yushkin, D. S. Nasonov, Astrophys. Bull. 63, 320 (2008).

[9] V. V. Kovtyukh, Mon. Not. R. Astron. Soc. 378, 617 (2007).
[10] Y. P. Georgelin, Y. M. Georgelin, Astron. Astrophys. 6, 349 (1970).

[11] D. L. Lambert, K. H. Hinkle, D. N. B. Hall, Astrophys. J. 248, 638 (1981).

[12] W. L. W. Sargent, Astrophys. J. 134, 1425 (1961).

[13] A. Lobel et al., Astron. Astrophys. 330, 659 (1998).

[14] A. Lobel et al., Astron. Astrophys. 291, 226 (1994).

[15] R. M. Humphreys, Astrophys. J. Suppl. 38, 309 (1978).

[16] V. G. Klochkova, E. L. Chentsov, N. S. Tavolganskaya, M. V. Shapovalov, Astrophys. Bull. 62, 105 (2007).

[17] N. E. Piskunov, F. Kupka, T. A. Ryabchikova, W. W. Weiss, C. S. Jeffry, Astron. Astrophys. 112, 525 (1995).

[18] F. Kupka, N. E. Piskunov, T. A. Ryabchikova, H. C. Stempels, W. W. Weiss, Astron. Astrophys. 138, 119 (1999).

[19] N. I. Gorlova et al., Astrophys. J. 651, 1130 (2006).

[20] K. Gesicki, Astron. Astrophys. 254, 280 (1992).

[21] R. M. Humphreys, K. Davidson, N. Smith, Astrophys. J. 124, 1026 (2002).

\title{
СПЕКТР ЖОВТОГО ГІПЕРГІГАНТА $\rho$ CAS ПРОТЯГОМ 2007-2011 pp.
}

\author{
В. Г. Клочкова ${ }^{1}$, I. А. Усенко ${ }^{2}$ \\ ${ }^{1}$ Спеціальна астрономічна обсерваторія РАН, м. Нижній Архис, 369167, Росія \\ ${ }^{2}$ Астрономічна обсерваторія Одесъкого націоналъного університету, \\ парк Т. Г. Шевченка, м. Одеса, 65014, Україна
}

\footnotetext{
Численні спостереження, виконані протягом 2007-2011 рр. за допомогою спектроскопї з високою роздільною здатністю на 6-м телескопі БТА САО РАН, дали змогу дослідити в деталях пекулярні особливості оптичних та ультрафіолетових спектрів і полів швидкостей в атмосфері жовтого гіпергіганта $\rho$ Cas. Радіальні швидкості, отримані за допомогою симетричних ліній поглинання металів, змінюються з часом стосовно до системної швидкості $V_{\text {sys }}=-47 \pm 1 \mathrm{~km} / \mathrm{c}$, та цей факт збігається з малоамплітудними пульсаціями атмосферних шарів поблизу фотосфери. В окремі моменти спостерігали градієнт швидкості в глибоких шарах атмосфери. Радіальна швидкість отримана за допомогою короткохвильових компонент Вa II, Sr II, Ti II та інших сильних ліній із низкими потенціалами збудження, наявна у вузькому ліміті $V_{\text {blue }} \sim-60 \div-70$ км/c. Ми припускаємо, що короткохвильові компоненти формуються в навколозоряній оболонці, точно так, як одна з компонент дублета ліній натрію D Na I.
} 